\title{
METHICILLIN RESISTANT STAPHYLOCOCCUS
}

\section{AUREUS (MRSA);}

PREVALENCE AND SUSCEPTIBILITY PATTERN OF (MRSA) ISOLATED FROM PUS IN TERTIARY CARE OF DISTRICT HOSPITAL OF RAHIM YAR KHAN.

\footnotetext{
1. MBBS, M.Phil (Microbiology) Associate Professor

Department of Pathology Sheikh Zayed Medical College, Rahim Yar Khan Punjab-Pakistan.

2. MBBS, M.Phil (Microbiology) Associate Professor

Department of Pathology Nishtar Medical College/ Hospital, Multan Punjab-Pakistan.

3. MBBS

Medical Officer

Sheik Zayed Hospital Rahim Yar Khan.
}

Correspondence Address: Dr. Muhammad Shahbaz Hussain Department of Pathology Sheikh Zayed Medical College, Rahim Yar Khan.

drmshahbaz@szmc.edu.pk

Article received on: 14/02/2018

Accepted for publication: 15/08/2018 Received after proof reading: 04/01/2019

\section{Muhammad Shahbaz Hussain', Abbas Naqvi², Muhammad Sharaz ${ }^{3}$}

ABSTRACT... Background: Methicillin resistant Staphylococcus aureus (MRSA) is one of the notorious bugs to cause nosocomial human infections worldwide. However its prevalence and susceptibility pattern quite varies in hospitals among different countries or within same country. Objectives: To study the prevalence and antibiotic susceptibility pattern of MRSA isolated from pus sample. Study Design: Cross sectional study. Period: 6 months. Setting: Tertiary care hospital of district Rahim Yar Khan -Punjab, Pakistan at its microbiology laboratory. Materials and Methods: A total 100 clinical specimen of pus and wounds were collected from various indoor and outdoor department of this institute. .The Staphylococcus aureus was identified on the basis of colony morphology, Gram's stain, and biochemical tests. Antibiotic susceptibility pattern was done according to CLSI guidelines. Results: Out of 100 clinical sample of pus and wounds, 21 coagulase positive staph. aureus were isolated, $14(66.7 \%)$ strains were found to be methicillin resistant and $07(33.3 \%)$ were found to be methicillin sensitive. Higher percentage of MRSA was isolated from surgical unit (66.7\%), indicating its nosocomial source of spread. Maximum resistance to MRSA isolate were developed to Amoxicillin/ clavulinic acid (80\%) followed by ofloxacin (71\%), cefoxitin (66.7\%), tetracycline (58\%), Ciprofloxacin (48\%), Erthromycin (46\%) and Amikacin (40\%). However, all strains were sensitive to vancomycin. Conclusion: There is high frequency of resistance among coagulase positive Methicillin resistant staph. aureus. Regular surveillance of hospital-associated infection and frequent monitoring of antibiotic sensitivity pattern is required to reduce MRSA prevalence.

Key words: $\quad$ MRSA, Prevalence, Antibiotic Susceptibility, Drug Resistance.

Article Citation: Hussain MS, Naqvi A, Sharaz M. Methicillin resistant staphylococcus aureus (MRSA); prevalence and susceptibility pattern of (MRSA) isolated from pus in tertiary care of district hospital of Rahim Yar Khan. Professional Med J 2019; 26(1):122-127. DOI: 10.29309/TPMJ/2019.26.01.2510

\section{INTRODUCTION}

Staphylococcus aureus is one of notorious microorganism that causes a wide variety of human diseases, from superficial skin infection to life threatening pneumonia, sepsis and endocarditis. Being a human commensal, it is difficult to eradicate and has a strong tendency to cause severe infection in both community as well as in hospitalized acquired patients. This increases morbidity as well as mortality and pose an enormous social and clinical burden on public health system in terms of treatment, hospital stay, equipment and isolation. ${ }^{1}$

Initially staphylococcus aureus responded well to the beta lactum group of antibiotics. Unfortunately MRSA (methicillin resistance staphylococcus aureus) have been reported in a very short period of time. Now a day's MRSA is resistant to most of the antibiotics used to treat ordinary staphylococcus infection. The global prevalence of hospital as well as community acquired MRSA infection continue to increase worldwide. ${ }^{2}$ Alteration in penicillin binding protein (PBP) and production of autolytic enzymes are the two main mechanism of resistance seen in MRSA associated infections. Moreover wide spread and irrational uses of antibiotics are its adding factors. So MRSA has become a serious threat and therapeutic challenge not only for clinicians but also for laboratory personal. ${ }^{3}$

Hospitals are one of the major sources of MRSA stain dissemination that leads to MRSA outbreaks both epidemically and endemically. Prolonged hospital stay, wide spread use of antibiotics, 
nursing home exposure, immune suppression, improper antibiotic dosage, indwelling catheterization, invasive medical device, drug abusers, unsterilized instrumentations are another predisposing factors to MRSA spread. MRSA is important health issue in both developing \& developed counties because it is contagious in nature and difficult to eradicate and treat. ${ }^{4-6}$

Prevalence and susceptibility pattern of MRSA isolates quite varies in hospitals among different countries or within same country. There was increase in prevalence of MRSA in United States over a period of 10 years from $32.7 \%$ in 1998 to $53.8 \%$ in 2007 and MRSA related hospitalization became doubled. ${ }^{7}$ European Sentry Study which constitute 25 hospitals showed MRSA isolates prevalence of $25 \%$ / which were more prevalent in South region. ${ }^{8}$

MRSA prevalence largely varies among 25 European countries hospital (5\% to $20 \%$ ) with highest variation found in Germany while Lowest in Slovenia. ${ }^{9}$ There is quite variation in prevalence of MRSA (22.6-77.6\%) in hospitals of many Asian countries too. ${ }^{10}$ The present study was conducted to prevalence of MRSA in tertiary care hospital of Rahim Yar Khan, Punjab-Pakistan.

\section{MATERIALS AND METHODS}

This cross sectional study of 6 month duration (January to June 2017) was conducted at tertiary care hospital of district Rahim Yar Khan -Punjab, Pakistan at its microbiology laboratory. A total 100 clinical specimen of pus and wounds were collected from various indoor as well as outdoor department of this institute. A careful history was taken and it was ensured that patients were not using any antibiotics.

A sample of pus was obtained after incision and drainage of abscess. A sterile cotton swab was used to collect pus from wounds if it was not discharging. The inner side of the infected wound was swabbed gently and it was transferred to microbiology laboratory for further processing. Special precautions were taken during collection of sample to avoid any contamination. All collected sample immerse in Amies transport medium was labeled and transported to the sterile laboratory profusion tube.

Inoculation of the samples was done on blood agar aerobically at $37^{\circ} \mathrm{C}$ for 48 hours. The identification of the staphylococcus stain was done on the basis of morphology, gram stain and other biochemical test following standard guidelines. A yellow to creamy 1-2 $\mathrm{mm}$ beta hemolytic colonies after overnight incubation on blood agar was used for preliminary identification.

\section{Antimicrobial Susceptibility Testing}

A standard disk diffusion technique on Muller Hinton agar (Oxoid) was used for the antimicrobial susceptibility testing of all isolates following Clinical and Laboratory Standards Institute(CLSI) guidelines Antibiotic impregnated disks (Oxoid) of amoxicillin(AM) $20 \mathrm{ug}: 10 \mathrm{ug}$, ciprofloxacin(CIP) $5 \mathrm{ug}$, amikacin (AK) $30 \mathrm{ug}$, erythromycin(E) 15 ug, vancomycin (VA) $30 \mathrm{ug}$, tetracycline(TE), ofloxacin and cefoxitin (FOX) 30ug were applied to the plates inoculated at $15 \mathrm{~mm}$ distance from the edge of the petri dish. Plates were inverted and incubated at $37^{\circ} \mathrm{C}$ in an incubator for 24 hours.

\section{Interpretation of Susceptibility Testing}

After an overnight incubation of 24 hours plates were examined to read the zones of inhibition by Vernier caliper and interpretation of results were done following were interpreted according to CLSI protocols. The strains of Staphylococcus aureus which were found to be resistant to cefoxitin were screened as MRSA.

\section{RESULT}

Clinical specimens were collected from various indoor as well as outdoor department of tertiary care hospital (Table-I). Out of 100 clinical specimens, $59 \%$ include pus and $41 \%$ wounds respectively. Out of $100,65 \%$ sample showed growth while $35 \%$ sample showed no growth on blood agar plates. Out of 65 growth sample, there were (27) gram positive cocci and (38) gram negative rods. From (27) gram positive cocci (21) was staphylococcus aureus and others were S.epidermidis, and Streptococcus species. Out of 21 S.aureus there were (14) MRSA and (07) 
MSSA (Table-II). Susceptibility pattern of MRSA and MSSA strains shown in Figure-1 and Figure-2 respectively.

\begin{tabular}{|l|c|c|}
\hline \multicolumn{1}{|c|}{ Ward } & Frequency & Percent \\
\hline surgical ward & 39 & 39.0 \\
\hline OPD & 29 & 29.0 \\
\hline Ortho ward & 13 & 13.0 \\
\hline Labor room & 19 & 19.0 \\
\hline Total & 100 & 100.0 \\
\hline \multicolumn{2}{|l|}{ Table-l. Sample distribution in different ward } \\
\hline
\end{tabular}

\begin{tabular}{|l|c|c|c|c|}
\hline \multicolumn{1}{|c|}{ Ward } & Frequency & $\begin{array}{c}\text { S. } \\
\text { aureus }\end{array}$ & $\begin{array}{c}\text { MRSA } \\
\text { No. (\%) }\end{array}$ & $\begin{array}{c}\text { MSSA } \\
\text { No. (\%) }\end{array}$ \\
\hline $\begin{array}{l}\text { Surgical } \\
\text { ward }\end{array}$ & 38 & 09 & $06(66.7)$ & $\begin{array}{c}03 \\
(33.3)\end{array}$ \\
\hline OPD & 30 & 08 & $\begin{array}{c}05 \\
(62.5)\end{array}$ & $\begin{array}{c}03 \\
(37.5)\end{array}$ \\
\hline $\begin{array}{l}\text { Ortho } \\
\text { ward }\end{array}$ & 13 & 01 & $\begin{array}{c}01 \\
(100)\end{array}$ & $\begin{array}{c}0 \\
(0)\end{array}$ \\
\hline $\begin{array}{l}\text { Labour } \\
\text { room }\end{array}$ & 19 & 03 & $\begin{array}{c}02 \\
(66.7)\end{array}$ & $\begin{array}{c}01 \\
(33.3)\end{array}$ \\
\hline Total & 100 & 21 & $\begin{array}{c}14 \\
(66.7)\end{array}$ & $\begin{array}{c}07 \\
(33.3)\end{array}$ \\
\hline
\end{tabular}

Table-II. Number and percentage of isolated MRSA and MSSA from different clinical samples

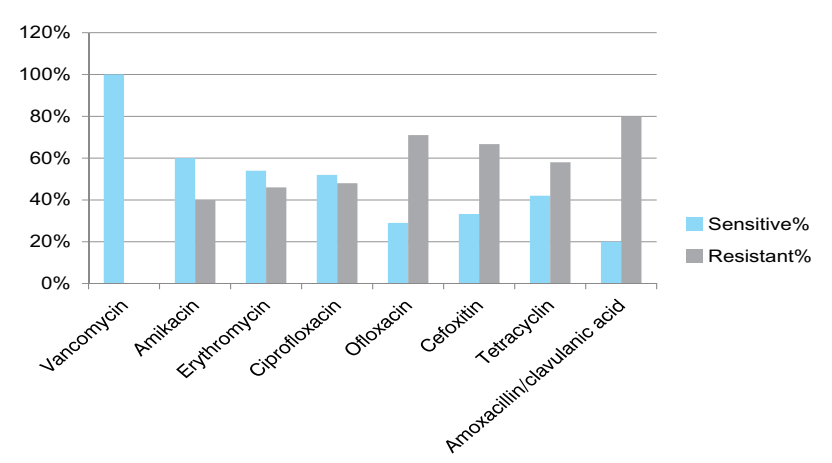

Figure-1. Susceptibility pattern of MRSA strain

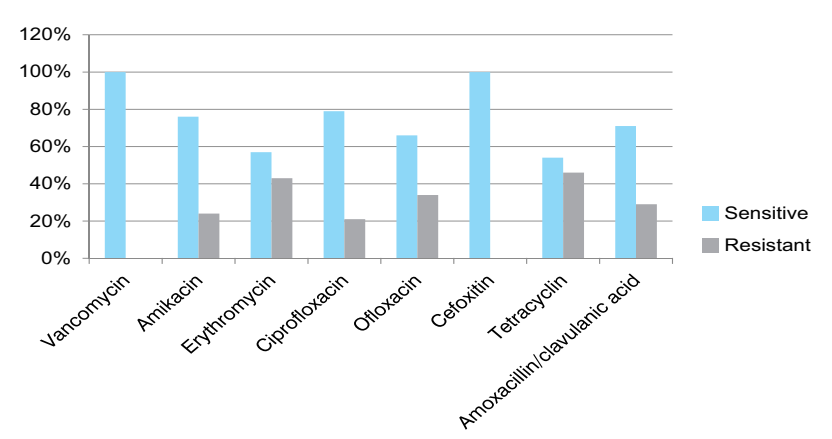

Figure-2. Susceptibility pattern of MSSA strain

\section{DISCUSSION}

Nosocomial MRSA infections become a challenge for scientists by emerging new antibiotics day by day against this notorious microorganism. MRSA infection not only leads to significant morbidity and mortality, but it also adds significant social and economic burden especially to hospitalized patients. Vancomycin is now only the drug of choice against this multi drug resistant MRSA, however a low level resistance is being reported to some extent from different region of world. ${ }^{11}$

There is wide variation in the prevalence of hospital acquired MRSA infection. Even in United States hospitals, where health care facilities are quite up to date, there was drastically increase in the number of MRSA isolates from $22 \%$ to $57 \%$ over a period of six years. ${ }^{12}$ Similar increase was noted in ICU setting, where MRSA isolate jumped from $35.9 \%$ to $64.4 \%$ within a decade..$^{13}$ There were reports of lower trend of MRSA hospitalization (2010-2014) too in United Sates, which reflect better control of skin and soft tissue infections. However hospitalization due to invasive MRSA remains unchanged. ${ }^{14}$ Europe too showed a quite variation in MRSA infection ranging from $1-50 \%$. MRSA infection prevalence in Europe is less than $5 \%$ in Denmark, Iceland, Netherland, Sweden and Norway. Some European countries showed above $25 \%$ MRSA prevalence such as Italy, United Kingdom, Romania, Spain, Turkey and Greece while Malta and Portugal showed above $50 \%$ MRSA prevalence..$^{15}$

On the contrary MRSA was highly prevalent in Asian countries with $25.5 \%$ as community acquired and $67.4 \%$ as hospital acquired. The highest prevalence of MRSA was seen in hospitals of China, Japan, Taiwan and Korea (70\%-80\%). ${ }^{10}$ Similarly India showed about 43\% MRSA infection from 15 tertiary care centres over a period of two year. ${ }^{16}$

There were limited studies conducted on MRSA prevalence in Pakistan. A study conducted in Islamabad showed $39 \%$ total prevalence of MRSA infection, with $35 \%$ in surgical ward and $65 \%$ surgical intensive care unit (ICU). Our study also showed $66.07 \%$ MRSA isolates from surgical 
ward including ICU indicating a source of its nosocomial spread. ${ }^{17}$

Most of the studies conducted in Pakistan revealed that overtime there was increase in the prevalence of MRSA infection i.e. Sargodha (23\%) in $1999,{ }^{18}$ Lahore (38.5\%) in 2001, ${ }^{19}$ Karachi (43\%) in 2005, ${ }^{20}$ and, Rawalpindi (50\%) in $2014^{21}$ and Karachi (52\%) in 2015-2017.22 Our study showed $66.03 \%$ MRSA prevalence which was quite high to above mentioned studies. A study conducted by Parveen et $\mathrm{al}^{23}$ showed high prevalence of MRSA (60.40\%) among five major government hospitals of Rawalpindi. A study conducted by Khan et $\mathrm{al}^{24}$ showed $53.3 \%$ MRSA prevalence in two major hospitals of Rawalpindi- Islamabad. Up till now high MRSA prevalence was found to be $71.1 \%$ in 2015 at National Institute of Health $(\mathrm{NIH})$, Islamabad. ${ }^{25}$ However, two studies which were conducted in Peshawar during 2012-2013 revealed very low MRSA prevalence (1-5.2\%). ${ }^{26,27}$

On the contrary a multicentre study conducted in Pakistan showed a geographical variation of MRSA infection being lowest MRSA resistance seen in Sukhur (2\%) followed by Quetta (26\%), Azad Kashmir (32\%), Rawalpindi -Islamabad (46\%) and highest resistance was seen in Lahore $(61 \%)$ \& Karachi $(57 \%)$ respectively. ${ }^{28}$ In above mentioned international and national studies, variations in MRSA prevalence caused by a number of factors in hospitals such as age, immune status, self medication, rationale use of antibiotics, prior hospitalization, hygienic condition of hospitals, population dynamics, health care facilities, implementation of infection control program and severity of infection.

Vancomycin showed $100 \%$ susceptibility to all MRSA strains in our study and no MRSA strain showed resistance to this antibiotic, which is comparable to other studies. Maximum resistance to MRSA isolates from pus samples in our study was developed to Amoxicillin/ clavulinic acid $(80 \%)$ followed by ofloxacin $(71 \%)$, cefoxitin (66.7\%), tetracycline (58\%), Ciprofloxacin (48\%), Erthromycin (46\%) and Amikacin (40\%). This was lower than previous other studies which may be due to better in hospital antibiotic policy. ${ }^{29,30}$ From our study, we can assume that glycopeptides is the drug of choice for the treatment of multidrug resistance MRSA stain. However it should be reserved for life threatening infection caused by MRSA.

Antibiotic resistance emerging at an alarming rate and becomes a health challenge in Pakistan. In order to prevent antibiotic resistance there is strong need to develop antibiotic stewardship which should be done by the mutual cooperation of clinicians, pharmacist and clinical microbiologist. Moreover strict policies should be made and implemented so that irrational use of antibiotics should be discouraged. Good hygienic conditions and local surveillance of antibiotics resistant profile on continuous basis is the best way to prevent MRSA infection. ${ }^{31}$

\section{CONCLUSION}

There is high frequency of resistance among coagulase positive Methicillin resistant staph. Aureus. Early detection of this nosocomial pathogen is also very necessary in asymptomatic colonized health care workers in hospital in order to prevent its dissemination and life threatening complications.

\section{Copyright@ 15 Aug, 2018.}

\section{REFRENCES}

1. Tong SY, Davis JS, Eichenberger E, Holland TL, Fowler VG. Staphylococcus aureus infections: Epidemiology, pathophysiology, clinical manifestations, and management. Clin Microbiol Rev. 2015; 28(3):603-61.

2. Bertrand X. Methicillin-resistant Staphylococcus aureus: An ever emerging threat. Therapy. 2010; 7(2):169-78.

3. Ippolito G, Leone S, Lauria FN, Nicastri E, Wenzel RP. Methicillin-resistant Staphylococcus aureus: the superbug. Int J Infect Dis. 2010; 14:S7-11.

4. McKinnell JA, Miller LG, Eells SJ, Cui E, Huang SS. A systematic literature review and meta-analysis of factors associated with methicillin-resistant Staphylococcus aureus colonization at time of hospital or intensive care unit admission. Infect Control Hosp Epidemiol. 2013; 34(10):1077-86.

5. Grundmann H, Aires-de-Sousa M, Boyce J, Tiemersma $\mathrm{E}$. Emergence and resurgence of meticillin-resistant Staphylococcus aureus as a public-health threat. 
The Lancet. 2006; 368(9538):874-85.

6. Uhlemann AC, Otto M, Lowy FD, DeLeo FR. Evolution of community-and healthcare-associated methicillinresistant Staphylococcus aureus. Infect Genet Evol. 2014; 21:563-74.

7. Mera RM, Suaya JA, Amrine-Madsen H, Hogea CS, Miller LA, Lu EP, Sahm DF, O'Hara P, Acosta CJ. Increasing role of Staphylococcus aureus and communityacquired methicillin-resistant Staphylococcus aureus infections in the United States: A 10-year trend of replacement and expansion. Microb Drug Resist. 2011; 17(2):321-8.

8. Fluit AC, Wielders CL, Verhoef J, Schmitz FJ. Epidemiology and susceptibility of 3,051 Staphylococcus aureus isolates from 25 university hospitals participating in the European SENTRY study. J clin Microbiol. 2001; 39(10):3727-32.

9. Tiemersma EW, Bronzwaer SL, Lyytikäinen O, Degener JE, Schrijnemakers P, Bruinsma N, Monen J, Witte W, Grundmann $H$, European Antimicrobial resistance surveillance system participants. Methicillinresistant staphylococcus aureus in Europe, 19992002. Emerg Infec Diseases. 2004; 10(9):1627.

10. Song JH, Hsueh PR, Chung DR, Ko KS, Kang Cl, Peck KR, Yeom JS, Kim SW, Chang HH, Kim YS, Jung SI. Spread of methicillin-resistant Staphylococcus aureus between the community and the hospitals in Asian countries: An ANSORP study. J Antimicrob Chemother. 2011; 66(5):1061-9.

11. Gardete S, Tomasz A. Mechanisms of vancomycin resistance in staphylococcus aureus. $\mathrm{J}$ Clin Invest. 2014; 124(7):2836-40.

12. Wisplinghoff $H$, Bischoff $T$, Tallent $S M$, Seifert $H$, Wenzel RP, Edmond MB. Nosocomial bloodstream infections in US hospitals: analysis of 24,179 cases from a prospective nationwide surveillance study. Clin Infect Dis. 2004; 39(3):309-17.

13. Klevens RM, Edwards JR, Tenover FC, McDonald LC, Horan T, Gaynes R, National Nosocomial Infections Surveillance System. Changes in the epidemiology of methicillin-resistant Staphylococcus aureus in intensive care units in US hospitals, 1992-2003. Clin Infect Dis. 2006; 42(3):389-91.

14. Klein EY, Mojica N, Jiang W, Cosgrove SE, Septimus $\mathrm{E}$, Morgan DJ, Laxminarayan R. Trends in methicillinresistant staphylococcus aureus Hospitalizations in the United States, 2010-2014. Clin Infect Dis. 2017; 65(11):1921-3.

15. Köck R, Becker K, Cookson B, van Gemert-Pijnen JE, Harbarth S, Kluytmans JA, Mielke M, Peters G, Skov
RL, Struelens MJ, Tacconelli E. Methicillin-resistant staphylococcus aureus (MRSA): Burden of disease and control challenges in Europe. Euro Surveill. 2010; 15(41):19688.

16. Ray P, Manchanda V, Bajaj J, Chitnis DS, Gautam V, Goswami P, Gupta V, Harish BN, Kagal A, Kapil A, Rao R. Methicillin resistant staphylococcus aureus (MRSA) in India: Prevalence \& susceptibility pattern. Indian J Med Res. 2013; 137(2):363.

17. Hussain S, Shams R, Ahmad K, Perveen R, Riaz B. Prevalence of methicillin resistant Staphylococcus aureus (MRSA) in surgical site infections in a tertiary care hospital. Journal Pathol. 2005; 3(2):81-5.

18. Siddiqui GM, Karamat KA, Hanan A. Prevalence of methicillin resistant staphylococcus aureus: $A$ study at PAF Hospital Sargodha. Pak J Pathol. 1999; 10:268.

19. Khatoon N, Bukhari MH, Riaz JR, Sheikh AS, Iqbal A, Naeem S. Prevalence of methicillin resistant staphylococcus aureus (MRSA) infection laboratory study at Mayo Hospital Lahore. Biomedica. 2002; 18:49-52.

20. Perwaiz S, Barakzi Q, Farooqi BJ, Khursheed N, Sabir N. Antimicrobial susceptibility pattern of clinical isolates of methicillin resistant Staphylococcus aureus. J Pak Med Assoc. 2007; 57(1):2.

21. Rashid A, Qureshi UR, Rashid A, Rashid H. Combating MRSA in Pakistan: An integrated drug therapy approach. American J Life Sci. 2015; 3(2):71-5.

22. Siddiqui T, Muhammad IN, Khan MN, Naz S, Bashir L, Sarosh N, Masood R, Ali A, Fatima S, Naqvi T. MRSA: Prevalence and susceptibility pattern in health care setups of Karachi. Pak J Pharm Sci. 2017; 30(6 (Supplementary)):2417-21.

23. Perveen I, Majid A, Knawal S, Naz I, Sehar S, Ahmed S, Raza MA. Prevalence and antimicrobial susceptibility pattern of methicillin-resistant staphylococcus aureus and coagulase-negative staphylococci in Rawalpindi, Pakistan. Br J Med Med Res.2013; 3(1): 198-209.

24. Khan S, Rasheed F, Zahra R. Genetic polymorphism of agr Locus and antibiotic resistance of Staphylococcus aureus at two hospitals in Pakistan. Pak J Med Sci. 2014; 30(1):172.

25. ur Rahman K, Ahmad A, Aziz A, Daud M, Khan I. Antibiotic susceptibility patterns of methicillin resistant staphylococcus aureus at national institute of health sciences, Islamabad, Pakistan. World J Zool. 2015; 10(4):318-22. 
26. Rafiq MS, Rafiq MI, Khan T, Rafiq M, Khan MM. Effectiveness of simple control measures on methicillin resistant staphylococcus aureus infection status and characteristics with susceptibility patterns in a teaching hospital in Peshawar. J Pak Med Assoc. 2015; 65(9):915-20.

27. Khan RA, Rahman AU, Ahmad A, Jaseem M, Jabbar A, Khan SA, Iqbal A, Ahmad N, Wadood A, Rahman TU. Prevalence and antibiotic susceptibility profile of methicillin-resistant staphylococcus aureus (MRSA) isolated from different clinical samples in district Peshawar. J Appl Environ Biol Sci. 2014; 4(8S):40-6.

28. Hafiz S, Hafiz AN, Ali L, Chughtai AS, Memon B, Ahmed A, Hussain S, Sarwar G, Mughal T, Awan A, Zaki K. Methicillin resistant Staphylococcus aureus: a multicentre study. J Pak Med Assoc. 2002 Jul; 52(7):312-4.
29. Rafiq MS, Rafiq MI, Khan T, Rafiq M, Khan MM. Effectiveness of simple control measures on methicillin resistant staphylococcus aureus infection status and characteristics with susceptibility patterns in a teaching hospital in Peshawar. J Pak Med Assoc. 2015; 65(9):915-20.

30. Bukhari SZ, Ahmed S, Zia N. Antimicrobial susceptibility pattern of staphylococcus aureus on clinical isolates and efficacy of laboratory tests to diagnose MRSA: A multi-centre study. J Ayub Med Coll Abbottabad. 2011; 23(1):139-42.

31. Huttner A, Harbarth S, Carlet J, Cosgrove S, Goossens $\mathrm{H}$, Holmes A, Jarlier V, Voss A, Pittet D. Antimicrobial resistance: A global view from the 2013 world healthcare-associated infections forum. Antimicrob Resist Infect Control. 2013; 2(1):31.

\section{NO MAN IS RICH ENOUGH TO BUY BACK HIS PAST.}

"Oscar Wilde"

AUTHORSHIP AND CONTRIBUTION DECLARATION

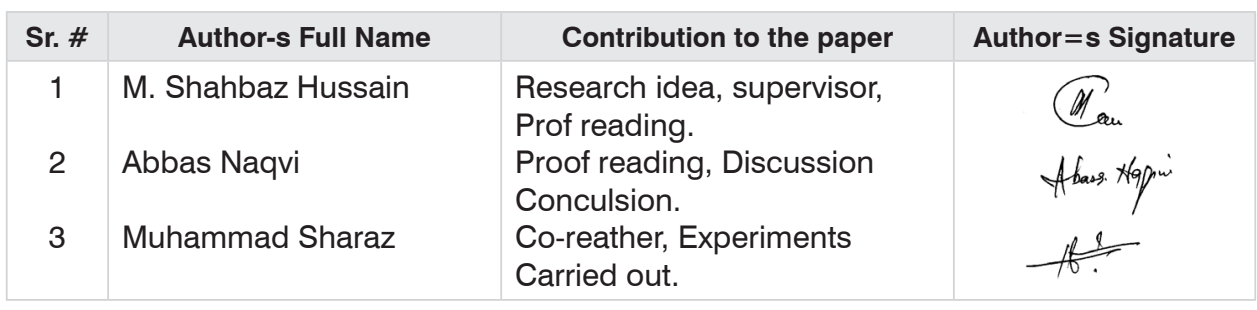

